\title{
SUSTAINABLE URBAN TRANSPORT ON THREE WHEELS
}

Mohammed Elius Hossein, Deputy Commissioner, Chottogram District, Bangladesh dcchit@mail.ee

Abstract

Many of our global warming problems come from transport. The majority of people who need transport the most in the developing world are too poor to pay for the highesttechnology vehicles which are not polluting. In the past 10 years, 3-6-passenger, batterypowered, Small Electric Passenger Vehicles (as this article is calling them, SEPVs) have appeared in major cities in the developing world. These slow, relatively safe, easily maneuverable, non-polluting and low-cost vehicles, on their three little wheels, are cutting the size of the world's transport carbon footprint. Recognize that this paper is only focused on carbon footprint: carbon emissions. It is not about "pollution in general" or "emissions in general". No other published article has explicitly considered the potential of the SEPV to contribute in reducing a nation's contribution to carbon footprint and thus to global warming. This article makes the case for building urban transport strategy and policy around such vehicles, in developing countries, in order to lower the countries' carbon footprint: that is its original contribution. The data showed that the SEPVs made a significant contribution to reducing the potential carbon footprint of transport in the small city of Cox's Bazar, in Bangladesh, proportionate to its population. The inference is that SEPVs could reduce the carbon footprint of the nation if they become a major, integrated part of urban transport in the megacities, which creates most of the country's carbon footprint. Other developing countries should study Cox's Bazar's example. India is already ahead of the game.

Keywords: sustainable urban transport; transport policy; auto-rickshaw, vehicle; developing countries; carbon emissions

\section{INTRODUCTION}

\subsection{Urban Transport and Global Warming}

Many of our global warming problems come from transport. One of the biggest contributors to greenhouse gas emissions is the internal combustion engine, in cars, vans, buses, taxis, lorries, even airplanes and ships. The oversized cities of developing countries, choked with carbon-emitting vehicles, contribute more to global climate change than do many cities in developed countries. The major cities in Europe, Japan, Australasia and North America use 
more underground rail and light rail, electric-driven trams and even, in recent years, bicycles, in the main roads, than do developing countries due to the higher level of wealth and, therefore, social capital, in the developed countries. The United Nations' climate change experts have explicitly recognized this problem of urban transport pollution in the developing countries (United Nations, 2018).

\subsection{Focus On Carbon Emissions}

This article is about how to shrink developing countries' urban transport carbon footprint, not how to make their air "cleaner in general". Without doubt, cleaning the air for health is important: but first, our planet must survive. It is carbon which is bonding with the ozone layer to expose the Earth to deadly ultraviolet radiation and the existential threat of climate change. When we have eliminated this existential threat to life on Earth then we can consider how to make transport healthier. Thus, the life cycle emission analysis for pollutants other than carbon is irrelevant here.

\subsection{Bangladesh and the SEPV}

Outside the biggest cities in Bangladesh, there are 8 smaller cities, which are regional ("Divisional") or District capitals. In most of these smaller cities, buses and private cars are almost unknown. The semi-urbanized towns needed something more than the rickshaw which has been their transport since the days of British India (1858 - 1947). The solution was a new type of vehicle. That vehicle is non-polluting, relatively safer than the pedal/battery rickshaws and provides cheap, relatively fast and plentiful urban transport for passengers in these small cities. There are many names for the vehicle in Bangladesh: "electric car", "easy-bike", "tom-tom", "auto-rickshaw", even, confusingly, "auto". Let us call it "small electric passenger vehicle" (SEPV) in this article, because this is most descriptive, and we need one consistent name.

The SEPV has three wheels but a rather spacious seating area: designed originally for two adults and two children plus a driver. The Bangladeshis put three adults in the adult seats, three adults in the children's seats and one passenger on each side of the driver, with children on their parents' laps or wedging in between two adults. The SEPV is electric driven, using a large battery that is charged with electricity from any household point overnight. In some towns, where the local Council interprets the Government's policy as banning all electric-driven vehicles (See section 1.5 below), for example, 
Chittagong City, the SEPVs run with methane gas canisters to obtain a local license. To put the SEPV's role in urban transport into context, in a typical District town in Bangladesh, Cox's Bazar, the site of our case study, a person has the following choices of urban transport other than walking, bicycling or private car: SEPV, "CNG" (equivalent to a Thai "tuk-tuk" but running on compressed natural gas), or one-seater rickshaw (pedal or battery).

\subsection{The Economics Of SEPVs}

The SEPV costs about US $\$ 2,000$ in Bangladesh. For its owner, the SEPV can generate as much as US $\$ 350$ gross income per month, in a country where the average monthly income was, in 2010, BDT11,479 (Bangladesh Bureau of Statistics, 2010) (US\$162 at the official exchange rate for that year of US\$1 = BDT71).

There are no financial expenses to operate an SEPV except to pay a driver, if the owner does not drive, and for overnight charging from the household electricity supply, plus any repairs needed. The payback period of less than one year is quite attractive, if the buyer can raise what is, in a developing country, the high cost of purchase, which must be in cash and almost never on credit.

The environmental cost of the electric-run SEPV is effectively zero because its emissions are zero. The argument has been made that the SEPV indirectly contributes to global warming when it runs on electricity which is generated from coal or fossil fuel. This would only be correct if the SEPVs were causing additional electricity to be generated. There is no evidence for this and, given the small amount of electricity used by SEPVs, by percentage, compared to the lion's share of electricity used by homes and industry, it is highly unlikely. In the short-term, electricity supply is relatively fixed and the SEPV is merely using electricity which homes and industry would have used anyway. The problem here is not the SEPV, which cannot be assigned the cost, but rather the electrical generation system, which is creating an environmental cost by using fuel which is contributing to global warming. If the electrical generation system used an environmentally sustainable fuel, no one would think to assign an environmental cost to the SEPV. Of course, those SEPVs, as in Kolkata or Chittagong, which run on some form of gas fuel, are uniquely contributing to carbon emissions and thus have an environmental cost. Yet that cost is arguably lower than the cost of alternatives that run on larger quantities of gas, or petrol, like cars, taxis or buses. 
The high volume of passengers in Bangladesh SEPVs makes them profitable for owners at a cost accessible to low-income passengers. For example, in Bangladesh, a passenger can ride in an SEPV, from one end of Rajshahi City to the other, a thirty-minute ride, for a total fare of only US\$0.25.

\subsection{SEPV - Bangladesh's Banned Solution}

The SEPV described here is not used in Dhaka and most in Chittagong operate illegally because Bangladesh banned SEPV imports in 2011. The Government's officially stated reason is that SEPVs use the nation's short electricity supply, which is needed for agriculture and industry (Ali, 2011). Also, the Government claimed that SEPVs were being charged from illegal connections to the electricity supply, so that the electricity was not even being paid for.

The Government may also have been influenced by competing transport (especially rickshaw) drivers, who are well-organized and can literally bring millions of voters to the polls on election day. While not available in the megacities, SEPVs somehow have become easily available in the smaller towns and certainly their numbers have increased since 2011. Actually, SEPVs can be found in Chittagong City (although the local government denies it) but in limited quantities. Yet one almost never sees SEPVs in Dhaka, presumably due to the ban. Dhaka is the capital: more Government policies are enforced there.

\section{MATERIALS AND METHODS}

\subsection{Hypothesis To Be Tested - SEPVs Can Reduce Urban Carbon Footprint}

The hypothesis in this paper is that more use of SEPVs in the cities of developing countries can mean less carbon emissions. This means that SEPVs can significantly reduce the carbon footprint of urban transport in developing countries, if allowed to operate freely and even more so if integrated into an environmentally sustainable urban public transport policy. Therefore, the argument of this paper is that:

(1) offering SEPV services should be legal;

(2) offering SEPV services should be encouraged as a matter of national policy; and

(3) when possible, an integrated urban public transport policy should be built around the SEPV as the primary mode of transport for short or 
medium-length trips, with the SEPV linked to access to buses or trains for longer trips.

If the hypothesis is proven, given the sustainable development goals and commitment of the world to reduce carbon emissions to slow global warming, the argument will follow.

\subsection{SEPVs In An Integrated Urban Public Transport Policy}

An urban transport system built around SEPVs means a system of fixed routes which can put an SEPV, on a timetable, within five minutes' walk of any home. With an organized system of routes and weather-sheltered stops within walking distance of all residential housing, running 24 hours per day, no one would need a taxi or a car. An electronic ticketing system, with payment to a machine at the SEPV stop, could ensure that each driver is paid fairly (by claiming on the tickets he collects) and that each passenger pays the right price.

If the SEPV near a passenger's house is not going to the passenger's destination, an urban transport policy would mean designated transfer points that passengers could use to travel from SEPV to SEPV until they reach their destinations. In large cities, the SEPV routes would have to be integrated with a system of buses or trains to prevent too many transfers and too much time for one journey.

Consider the example of Hossain: he lives at the South end of South Dhaka City, in Shyampur, and he needs to go to work in one of the many garment factories in the area of Tongi, just outside the north end of North Dhaka City. How would an integrated urban transport policy help him get to work?

He leaves his house at $7 \mathrm{am}$. He can walk to the SEPV transport shelter near his house in Shyampur, where SEPVs leave and arrive at 7.00, 7.15, 7.30, 7.45 and 8.00 am. He can catch the 7.15 am SEPV there and go to the Shyampur hub by $7.30 \mathrm{am}$. There he transfers to an articulated solar-electric tram going from hub to hub until it reaches Kamlapur, the train terminal, at $8.15 \mathrm{am}$. Then he boards a high-speed intra-city train going to Tongi at $8.20 \mathrm{am}$, arriving at Tongi rail station at $8.45 \mathrm{am}$. From there he takes another SEPV to his workplace gate before his start time at $9 \mathrm{am}$.

Now Hossain could not think of such a trip: or it would take 4 or 5 hours. Traffic jams, full buses or even floods on rainy days prevent such seamless travel. Of course, a rich person could pay a polluting CNG tuk-tuk's driver US\$30 to navigate all the side lanes around the traffic jams and floods and arrive at his destination maybe only 1 hour late. But Hossain can only dream of that. 
He can pay maximum US $\$ 1$ per day, as his income is about US $\$ 100$ per month. With an integrated urban transport system almost everyone in the city used daily, that price could be possible. That is about what he pays now, not expecting seats on any bus and sometimes holding on to the door or window, outside the body of the bus, as the bus travels. And every bus he uses is a big carbon emitter.

Note that the full-fledged integrated urban transport policy envisioned here is for the future. Dhaka has, today, no SEPVs, no solar-electric trams and its trains are few and full of inter-city passengers. However, we are talking about what is possible someday if the Government wanted to have such a policy, like Kolkata, India's, referred to later. Such a policy could start with legalizing the SEPVs, so at least Hossain has some alternatives at the beginning and end of his bus-to-bus living nightmare.

\subsection{The Case Study}

The fundamental hypothesis, that the SEPV is better for the nation's carbon footprint than the bus or taxi, has been tested in this article by calculating how much in carbon emissions the SEPVs prevent in one smaller city, Cox's Bazar, Bangladesh, where they are used extensively. Presently, the modes of transport available in Cox's Bazar are:

(1) SEPVs (local name "tom-tom") - used in two ways:

(a) classified by the driver per trip (meaning, it can be in class (a) on one trip and in class (b) on the next trip) as "reserve" - meaning the driver allows only one passenger at a very high ("agreed") price, like a taxi with no meter

(b) classified by the driver per trip (see meaning above in (a)) as "local" meaning that anyone can board and the fare is fixed customarily at 5Tk or 10Tk (US\$0.06 - US\$0.10) according to the distance of the journey, which is not calculated or measured in minutes or kilometres but just by custom (travel from a to b is 5Tk, travel from a to $\mathrm{c}$ is $10 \mathrm{Tk}$ ) or whatever the driver can convince the passenger to pay, with a maximum capacity of 8 persons

(2) A small vehicle, fuelled by liquid compressed natural gas, somewhat resembling the Thai "tuk-tuk", with a maximum capacity of three persons in the back seat (local name " $C N G$ ") 
(3) A few city buses (less than 5), fuelled by petrol and mainly running trips between Cox's Bazar Town and nearby villages in Cox's Bazar District, (although it is possible to board and alight for a short intratown journey) only in a few major roads (local name "bus" or "citybus")

(4) Other vehicles or modes for personal transport of its owner only bicycles, SUVs, automobiles, walking

It would have been better to have tested the hypothesis in a larger city, like the capital Dhaka: but SEPV's are banned there. Even in Chittagong, the second largest city, only SEPVs which were licensed in 2011 and running on gas cylinders can be licensed, which is a small number. As most SEPV usage is in the smaller cities of Bangladesh, we only have this comparatively small population to use as a test case.

Then those results are projected to estimate how much replacement of taxis and buses by SEPVs could reduce carbon emissions in Dhaka, if SEPVs were allowed to be used. Then the estimated reduction of the carbon footprint by greater use of SEPVs in Dhaka is extrapolated to estimate the possible effect on the carbon footprint of Bangladesh. This approach can serve as a model for similar calculations in any developing country.

\section{THEORY/CALCULATION}

\subsection{Conclusions From The Theoretical Review}

An extensive review of all the published literature on the issue of reducing carbon emissions in cities in developing countries through use of alternative vehicles and substitution of vehicles which emit large amounts of carbon, suggests the following conclusion.

- While there has been a lot of interest in the SEPV, especially in developing countries (including Bangladesh), there has never been a systematic attempt to measure the extent to which SEPVs reduce the carbon footprint of urban transport in a country. This fact suggests a need for the research conducted for this paper. The nearest other researchers have come include: (Centre for Policy Research, 2018); (Pai, 2018); (Climate Finance Lab, 2018); (Tarulescu, 2017); (Rana, 
Hossain, Roy and Mitra, 2013); (Iqbal, Akhter and Ahmad, 2013); (Mani, Pai and Aggarwal, 2012); (World Resources Institute, 2012)

- Literature about use of SEPVs in India supports the hypothesis of this article that such vehicles can reduce the carbon footprint of urban transport in large cities of the developing world while providing an accessible, affordable and effective form of transport in developing countries like India. (Centre for Policy Research, 2018); (Pai, 2018); (Climate Finance Lab, 2018); (Mani, Pai and Aggarwal, 2012); (World Resources Institute, 2012)

- There is substantial support for the conclusion that electric vehicles can make a significant contribution to reducing carbon emissions. (Faisal, 2016); Transportation Research Board, 1996); (Replogle, 1992);

- There is substantial support for the conclusion that carbon emissions can be reduced by substituting more-emitting with less-emitting vehicles. (Bus Industry Confederation, 2018); (Tarulescu, 2017); (International Association of Public Transport, 2014)

- As proposed in this article, SEPVs are most-effectively used when integrated into an urban transport policy and where there is some incentive or assistance to get owners of other forms of transport to purchase electric SEPVs. (Centre for Policy Research, 2018); (Climate Finance Lab, 2018); (Kokaz and Rogers, 2000); (Replogle, 1992)

\subsection{Calculation}

This study tested the hypothesis that battery powered SEPVs would reduce the net carbon footprint of transport in Bangladesh cities. To test the hypothesis, first we had to estimate how much the SEPVs in the smaller cities are reducing carbon emissions. If the SEPVs cannot significantly reduce the carbon footprint of urban transport, there is no ecological reason to increase their use, notwithstanding their other advantages.

\subsubsection{Data Collection}

To test the hypothesis, we have measured the number of passengers served and kilometers traveled (via minutes transporting passengers in a typical day) in the Bangladesh city of Cox's Bazar. First, research assistants attended at all SEPV terminals (12) in Cox's Bazar to count the number of SEPVs at the 
terminals, at about the same time, on one day. From this observation, and on the advice of the local Pourashava (Village Council) staff, we estimated the total number of SEPVs at 5,000 in Cox's Bazar.

On another day, assistants attended at the same terminals with logbooks. Each assistant rode one SEPV for about two hours in the morning and two hours in the afternoon, logging each passenger and the duration of his/her journey.

In Cox's Bazar City, data was collected from a total of 353 SEPVs. This means that the sample size is $353 / 5,000$. That is just 4 cars short of the 357 needed to give us a confidence level of .95 with a confidence interval of $5 \%$ (Survey System, 2018). We can thus be highly confident that the number of passengers and their length of journeys will be represented by this sample.

\subsubsection{Summary and Analysis of Data}

\subsection{Average journey time per passenger (in kilometers)}

The number of passengers and the minutes of journey time were summed and then divided:

\section{$\underline{\text { Total Journey Time (Minutes) }}$ \\ Total Passengers}

Total journey time, in minutes, was 60,294 and the total number of passengers was 17,246. This produced an estimate that an average passenger in an average SEPV rode 3.5 minutes for a journey. This is consistent with (Rana, Hossein, Roy and Mitra, 2013)'s finding that $85 \%$ of the SEPV trips were less than $5 \mathrm{~km}$ long.

If we assume, as we have observed, that the average SEPV in Bangladesh in a small-town travels at about $25 \mathrm{~km}$ per hour or $0.42 \mathrm{~km} /$ minute then in 3.5 minutes would travel $1,47 \mathrm{~km}$.

Therefore, the average journey in a SEPV in Cox's Bazar was 1.47 kilometers long. confirmed.

Note that, as $1.47 \mathrm{~km}<5 \mathrm{~km}$, (Rana et al, 2018)'s finding is again 


\subsubsection{Carbon Dioxide Emissions Reduction By Use of SEPVs in Cox's Bazaar}

\subsection{Assumptions}

To estimate how much carbon emission the fact that the passengers were riding SEPVs, instead of petrol-driven buses or cars, was saving in Cox's Bazar, we needed an emission/bus/hour figure and an emission/car/hour figure to compare. First, the emission/bus/hour was calculated, multiplied by the number of buses we expect would have been used (Eb).

As there are few private cars in Cox's Bazar (most cars belong to State agencies or NGOs) and there are no petrol taxis (SEPVs declaring themselves "reserve" and taking only one passenger at a time, serve this function), we assumed that most would have ridden buses if there had been no SEPVs, as usually happens in Dhaka. Some wealthy people do have cars or SUVs but they rarely ride SEPVs, especially what are called "local" SEPVs that we are talking about here. Therefore, they would not have been counted as SEPV "passengers" in our survey. If the wealthy ride an SEPV, e.g. to the airport or the intercity bus terminal, they take a "reserve" SEPV, as described above, as the substitute for a taxi. There are "local" CNG tuk-tuks, that emit some carbon, but their capacity is limited, and their price is higher: they could not take many of the SEPV passengers and not many of the SEPV passengers would switch to them if lowprice buses were available.

However, the use of buses as a comparator for carbon emissions of SEPVs should not be taken as advocating that buses - whether petrol or electric - are a viable alternative for SEPVs. Buses make financial sense in large conurbations where they can count on large numbers of passengers every day. Cox's Bazaar is lightly populated and the population is rather far-flung, in small village-like neighborhoods. Buses would probably not gather a sufficient ridership to become financially viable. The SEPV does not need so many passengers at a time and can go in many different directions in one day. Perhaps that is why there are SEPVs almost everywhere in Cox's Bazaar and only five buses.

As to walking, first note that Cox's Bazar is the southernmost part of Bangladesh, near Thailand and Malaysia, so the weather is hot, humid and not conducive to a lot of walking. Certainly, a lot of walking occurs in Cox's Bazar, some walks much farther than we might expect, due to the shortage of SEPVs (most that are not "reserve" are full most of the time). If there were low-price, high-capacity buses available often to reach most destinations, it is more rational 
to assume that less people would walk than do so now, than to assume they would protest with their feet against the loss of their beloved SEPVs by taking to the footpaths. In this article we are mainly concerned with transport policy, not how people might travel with no transport at all.

There are few bicycles in Cox's Bazar. They are rather costly for the average town-dweller to buy and bicycling in the hot sun and humid air can be an uncomfortable prospect. Whether or not the culture could be changed to accept more bicycling is a hypothetical question. Probably some subsidy would be required to induce town-dwellers to purchase a bicycle rather than pay a small amount for each trip as they do for the SEPV. Again, this is not a question of public transport, which is the subject of this paper.

\subsection{Calculations}

First, we need an estimate of how many buses would ply the roads if they replaced the SEPVs in Cox's Bazar. (Katz and Rahman, 2010, p. 87) found that, studying the local (people get on and off the bus at will and pay the conductor) and ticket (people buy tickets before boarding the bus and the seats are usually not oversold: they also make less stops on the route) buses of Dhaka, that local buses transported 117 persons per hour and ticket buses 70 per hour. There is a strong argument that the buses which would replace SEPVs in Cox's Bazar would be local buses because the users are poor and are attracted to the low price of the non-reserved SEPV. They would be less likely to be attracted to a more-expensive ticket bus replacement. There are a few local "Citybuses" but no ticket buses in Cox's Bazar now, so we presume that people would continue to do as they have done before.

Concluding, let us assume that the buses would be local buses and would transport 117 persons per hour. Note that the maximum capacity of a "local" SEPV is 8 passengers at a time. They take the average passenger on a 3.5minute journey: so, at a maximum they would carry:

60 minutes/3.5 = 17.14 "runs"/ hour

If the SEPV is full for every run, it would transport:

8 passengers $\mathrm{x} 17.14$ runs $=$ maximum 137 passengers/hour

It is true that this result may be high because it comes from Dhaka, where the population is denser and the distances are longer. Yet it is also true that the travel distances of the SEPV passengers in Cox's Bazar are rather short: 1.47 $\mathrm{km}$, so perhaps more people than in Dhaka would be jumping on and off the local buses in Cox's Bazar. However, estimating the total number of passengers, beyond the figures we have available, would be mere guesswork. 
(Wadud and Khan, 2010) calculated that the emission of $\mathrm{CO}^{2}$ from a diesel bus was $887 \mathrm{~g} / \mathrm{km}$ (as well as $0.06 \mathrm{~g} \mathrm{CH}^{4}$ ) and the emissions from a CNG bus was $968 \mathrm{~g} / \mathrm{km}$ (as well as $8.49 \mathrm{~g} \mathrm{CH}^{4}$ ). As (Alam and Hoque, $2018 \mathrm{p}$. 1056) found that $61 \%$ of buses were $\mathrm{CNG}$ and $39 \%$ were diesel, let us make a weighted average emission with these factors:

$$
968(.61)+887(.39)=590+346=936
$$

This means that we estimate that the average bus in Cox's Bazar would emit $936 \mathrm{~g}$ of $\mathrm{CO}_{2}$ per $\mathrm{km}$ travelled.

As stated at the start of this Methodology section, the research assistants recorded a total of 60,294 minutes for all journeys in a day in their sample (see section 3.2.1 above). This was 60,294 minutes for 353 SEPVs that they sampled. From this, we can infer that the day's travel per SEPV was:

$$
60,294 / 353=171 \text { minutes per SEPV }
$$

If we multiply the estimated total number of SEPVs, 5,000, by the average number of minutes per car, we will get:

$$
5,000 \times 171=855,000
$$

This means that all SEPVs are on the road an estimated total of 855,000 minutes per day in Cox's Bazaar. Let us divide this by 60 to talk in terms of hours, not minutes.

$$
855,000 / 60=14,250 \text { hours }
$$

This means that we estimate that all SEPVs in Cox's Bazar are on the road 14,250 hours per day. At their speed of $25 \mathrm{~km} /$ hour, we have:

$$
14,250 \times 25=356,250 \mathrm{~km}
$$

This means that we estimate all the SEPVs in Cox's Bazar travel 356,250 $\mathrm{km}$ per day. Now, let them all be replaced by buses travelling the same distance: we multiply our weighted average emission per km, 936g, by the total estimated number of $\mathrm{km}$ travelled per day, $356,250 \mathrm{~km}$.

$$
936 \mathrm{~g} \text { x 356,250km }=333,450,000 \mathrm{~g}
$$

First, let us talk about $\mathrm{kg}$ not $\mathrm{g}$, by dividing by 1,000 :

$$
333,450,000 / 1,000=333,450 \mathrm{~kg} / \text { day }
$$

Now, let us multiply the day figure by 365 to get the amount of emissions of $\mathrm{CO} 2$ one year from a diesel bus-based system:

$$
333,450 \times 365=121,709,250 \mathrm{~kg} / \mathrm{year}
$$

We would normally subtract the SEPV emissions from this derived bus figure, to get the increase in emissions from the buses. However, an SEPV has zero emissions, so we have nothing to calculate.

If the current number of SEPVs were not on the road in Cox's Bazar, replacing buses, there would be almost 122 million kgs more carbon emissions 
per year in the village. To put it in perspective, the total carbon emission of Bangladesh in 2014 was 73,190 kilotons (Global Economy, 2014): that equals 73.19 billion kilograms. Therefore, the SEPVs are reducing Bangladesh's $\mathrm{CO}_{2}$ emissions in Cox's Bazar by $1.7 \%$. That is a small amount but bear in mind that Cox's Bazar's population is only $1.63 \%$ of Bangladesh's total. The SEPVs are pulling the village's weight in carbon emission reductions.

\subsubsection{Possible Impact of SEPV Use In Dhaka}

To estimate how much carbon emission would be saved if all buses and cars in Dhaka were replaced by SEPVs, we needed figures for total bus and car carbon dioxide emissions now in that city. As the SEPVs emission is zero, summing these bus and car figures, gives us the estimated total carbon dioxide emissions which would be saved due to SEPVs replacing buses and cars in Dhaka (DECO2). This will give us a better idea of the unused potential of SEPVs to reduce the carbon footprint of transport in Bangladesh. (Labib et al, 2013, p. 142-143) estimated that, in Dhaka, in 2009:

Total bus emissions in Dhaka $=2,223.95$ tons $/$ day $=397.61$ tons +1359.16

$$
\text { tonnes }=2621.56 \text { tons/day }
$$

Total taxi emissions in Dhaka $=378.68$ tons/day

"Autorickshaws" (probably CNG tuk-tuks) $=320.67$ tons/ day

If we sum all of these, which are the most likely vehicles that SEPVs could attract from, we get:

$$
2621.56+378.68+320.67=3,320.91 \text { tonnes/day }
$$

Multiply by 365 to get an annual figure and we have:

$$
3320.91 \times 365=1,212,132.15 \text { tonnes/year }
$$

Convert this to kilotonnes and we have: 1212.13 kilotonnes. (Kyle's Converters)

The total carbon emission of Bangladesh in 2009 was 53,736 kilotons (Global Economy, 2009).

This implies that, if all the bus, taxi and autorickshaw passengers in Dhaka had converted to SEPVs in 2009, that would have reduced Bangladesh's carbon footprint by 1,212 kilotonnes or $2.3 \%$. Perhaps not all of the other vehicles' passengers would transfer to SEPVs but it is impossible to estimate 
how many would do so. Much more than SEPVs will be needed to reduce Bangladesh's carbon footprint significantly but it would be a step forward.

If we take the example of Kolkata, a city of similar size and culture (Centre For Policy Research, 2018), it is reasonable to assume that SEPVs could become the major mode of transport in Dhaka, if legalized and allowed to operate freely, more so if Dhaka had a policy of integrating the SEPVs into an integrated urban transport policy.

\section{RESULTS AND DISCUSSION}

It is notable that, even though they were calculated on totally different bases, the contribution of the SEPVs to reducing the carbon footprint was estimated as relatively the same both in Cox's Bazar (1.63\%) and in Dhaka (2.3\%). Thus, we can infer that an integrated public transport policy across the country, built around SEPVs, would reduce the carbon footprint of Bangladesh by about $2 \%$.

Of course, we cannot expect the SEPVs to solve Bangladesh's carbon emissions problems by themselves, but $2 \%$ is a significant and welcome step forward. At least this result would justify legalizing SEPVs and studying their use to see what they would actually contribute to reducing carbon emissions in Dhaka.

Regarding the Government's stated concern about SEPVs electricity usage, such legalization could be combined with better security measures to stop theft of electric power and converting electric power from petrol-based to solar, wind, nuclear and other sources to assure that the SEPVs are not contributing to global warming by using fossil-fuel-generated electricity while reducing carbon emissions.

\section{CONCLUSIONS AND RECOMMENDATIONS}

\subsection{A Potential To Reduce Carbon Emissions - Which Is Significant But Not Necessarily Quantifiable Before The Potential Is Utilized}

Of course, the reduction of carbon dioxide emissions that would actually occur with an urban transport policy built around use of SEPVs in Bangladesh, or in any developing country, cannot be predicted with precision. There are too many unknown variables in the future to talk in any more than possibilities. "How many people, from which modes of transport, would change to SEPVs?" 
is the main unknown variable and we can only argue and make hypotheses about it now.

Yet this study does suggest rather clearly that the potential for SEPVs to contribute to carbon dioxide emission reductions is significant, by substituting a no-emissions vehicle for high-emissions vehicles. The estimate here is that something like $2 \%$ of the national carbon footprint could be eliminated. While the real effect on the carbon footprint must be a matter for speculation, the argument is based on logic and on extrapolating the use of SEPVs in a small town like Cox's Bazar to use in a large conurbation like Dhaka, based on what we know about urban transport in Cox's Bazar and in Dhaka.

\subsection{The Current Government Policy Of Banning SEPVs Wastes An Opportunity To Reduce Urban Transport's Carbon Footprint}

The Government's policy in Bangladesh of trying to ban SEPVs is thus wrongheaded. It has thrown away a major opportunity to reduce the carbon footprint of transport in the big cities where that carbon footprint is largely created. Moreover, outside the big cities, where SEPVs are most needed to provide cleaner, safer, smaller, more comfortable transport, the policy has largely failed because it has been ignored.

The argument that the SEPV should be banned because perhaps some owners hooked up SEPVs to the power system without paying for the power is not logical. If the SEPV owners are stealing the electricity to run their vehicles, that is a problem of the security of the power supply, not of the SEPV. The Power Boards should certainly make sure that no one can use power without paying for it, but it does not follow that all SEPVs, whether or not they pay for their electricity used, should be taken off the streets.

The Government of Bangladesh should take the opportunity to reduce urban transport's carbon footprint by legalizing the SEPVs and then building integrated urban transport policies around the SEPV for short urban trips and intra-urban electric trams, buses and trains for longer urban trips.

What is an "integrated urban transport policy"? The idea is to look for other cities, such as Calcutta. It is a seamless web of transport that allows anyone in the city to travel from one place to another by transferring from one mode of transport to another at "hubs", with little waiting time because the arrival and departure times of the modes of transport at each hub are synchronized. 
And what would be the effect of the integrated urban transport system on our main point of interest, carbon emissions? It is simple logic to suggest that moving from carbon-emitting buses, CNG-tuk-tuks, taxis and single-user cars, which predominate in Bangladesh's cities today, to non-emitting SEPVs and other non-emitting vehicles like trams and trains, there must be a smaller carbon footprint from urban transport as a result.

The effect of an integrated urban transport policy, based on SEPVs and other electric vehicles on reducing carbon emissions, could be enhanced by incentives such as financial assistance to replace petrol taxis, Compressed Natural Gas tuk-tuks and petrol "human haulers" (dollar vans) with SEPVs, as was done in India (Climate Finance Lab, 2018). That would be a positive incentive to get non-emitting SEPVs on the road and carbon-emitting vehicles off the road. A more-negative incentive would be to impose intra-urban tolls on petrol vehicles, as London has done with its "congestion charge" (Bloomberg, 2018). These are creative, effective initiatives to reduce the carbon footprint of urban transport.

Banning the SEPVs is neither positive nor effective policy and it increases the carbon footprint of urban transport. This ban contributes to global warming by wasting the opportunity to reduce the carbon footprint of urban mass transport. In Dhaka, the huge conurbation whose ecological footprint of transport alone exceeds its ecological capacity to absorb carbon by 70 times (Labib et al., 2013: p. 144), the ban is effective. What that means is that the banned, environmentally friendly SEPVs have been replaced by smoke-belching buses, private cars and taxis, complemented by a few Compressed National Gas tuk-tuks, with quite limited capacity of three passengers or less for a trip, which still produce some carbon emissions. In Chittagong, the smaller of the top two cities in population, the ban is slightly less effective: some SEPVs run, legally with gas canisters producing some carbon emissions or illegally with electric batteries, on limited routes in the city, producing no emissions. In both the major cities, the ban prevents one method of reducing the carbon footprint of urban transport, the SEPV, from achieving its full potential to do so.

\subsection{General Conclusion}

Other developing countries should study the example of little Cox's Bazar. We have found that its reduction of the carbon footprint due to SEPVs is proportional to its percentage of the national population. If those results would be replicated after the legalization of SEPVs in the large conurbations, which 
have most of the nation's population, we could expect a large decrease of the national carbon footprint. Some countries, like India, are already moving in that direction, of basing their transport more on SEPVs, to provide cleaner, safer, more comfortable and passenger-focused transport in their cities, to save their nations and save the Earth. Many other countries, including Bangladesh, which has been one of the world's leaders in advocating action against climate change, are obliged to do so.

\section{REFERENCES}

[1] Ali, T., (2011) "Electric Cars Run Out Of Steam", Daily Star (30.5.2011) https://www.thedailystar.net/news-detail-187825.

[2] Bangladesh Bureau of Statistics (2010), Report of the Household Income and Expenditure Survey, p. 27.

[3] Bloomberg (2018) https://www.bloomberg.com/news/articles/2018-04-11/london-scongestion-charge-is-showing-its-age.

[4] Bus Industry Confederation, Climate Change and Public Transport http://bic.asn.au/information-for-moving-people/climate-change-and-public-transport (Accessed 4.7. 18).

[5] Centre for Policy Research, Innovative Transport Solutions, Centre for Urban Economic Studies, Shakti Sustainable Energy Foundation INTEGRATING INTERMEDIATE PUBLIC TRANSPORT WITHIN TRANSPORT REGULATION IN A MEGACITY http://cprindia.org/sites/default/files/policybriefs/INTEGRATING_IPT_WITHIN_TRANSPORT_REGULATION_IN_A_MEGA CITY_KOLKATA.pdf (Accessed 29.7.18).

[6] Climate Finance Lab, https://www.climatefinancelab.org/project/low-carbon-autorickshaws/ (Accessed 1.6.18).

[7] Faisal, F. "An Analysis Of Electric Vehicle Trends In Developing Countries" (2016) 9 Journal Of Undergraduate Research 1.

[8] Global Economy, 2009 https://www.theglobaleconomy.com/Bangladesh/Carbon_dioxide_emissions/

[9] International Association of Public Transport, Climate Action And Public Transport (2014).

[10] Iqbal, M., Akhter, S. and Ahmad, S., "Study On Merits And Demerits Of Two Transport Systems (2013) 5(5) IOSR Journal Of Mechanical And Civil Engineering 25. 
[11] Katz, D. and Rahman, M., "Levels of Overcrowding in Bus System of Dhaka, Bangladesh", Transportation Research Record: Journal of the Transportation Research Board, No. 2143, Transportation Research Board of the National Academies, Washington, D.C., 2010, pp. 85-91.

[12] Kokaz, K. and Rogers, P., in URBAN TRANSPORTATION FOR AIR QUALITY MANAGEMENT

https://www.seas.harvard.edu/TransportAsia/workshop_papers/Kokaz.pdf (Accessed 15.6.18).

[13] Labib, S., Mohiuddin, H., Shakil, S., "Transport Sustainability Of Dhaka” (Dec 2013) 6 Journal Of Bangladesh Institute of Planners 137.

[14] Mani, A., Pai, M., and Aggarwal, R., "Sustainable Urban Transport In India”, World Resources Center, Ross Institute Washington (USA) (Feb. 2012).

[15] Pai, M., "Assessing The Role Of In Sustainable Urban Transport For Indian Cities", http://siteresources.worldbank.org/EXTURBANTRANSPORT/Resources/3414481296493837095/Motorcycle_Pai_TT2011.pdf. (Accessed 21.6.18)

[16] Rana, M., Hossein, F., Roy, S., and Mitra, S., "Exploring Operational Characteristics Of Battery-Operated Auto-Rickshaws In Urban Transportation System" (2013) 2(4) American Journal Of Engineering Research 1.

[17] Replogle, M., NON-MOTORISED VEHICLES IN ASIAN CITIES (1992) World Bank Technical Paper No. 162, http://documents.worldbank.org/curated/en/191771468770663924/pdf/multi-page.pdf.

[18] Tarulescu, S. et al., "Smart Transportation CO2 Emission Reduction Strategies" (2017) 252 I.O.P. Conf. Series: Materials Science and Engineering 012051.

[19] Transportation Research Board, in MEETING THE CHALLENGES OF MEGACITIES IN THE DEVELOPING WORLD (1996).

[20] United Nations, https://unhabitat.org/urban-themes/climate-change/ (Accessed 1.6.18).

[21] Wadud, Z. and Khan, T., "CNG Conversion Of Motor Vehicles In Dhaka" (2010) https://www.bangladeshenvironment.com/index.php/others/299-cng-conversion-of$\underline{\text { motor-vehicles-in-dhaka-valuation-of-the-co-benefits }}$

[22] World Resources Institute, https://www.wri.org/our-work/top-outcome/indian-citylaunches-pioneering-auto-rickshaw-service. (Accessed 25.6.18). 